http://www.jfas.info

\title{
THE MECHANICAL CHARACTERISTICS OF POLYMER CONCRETE USING POLYESTER RESIN
}

\author{
A. Ghiami Bajgirani ${ }^{1}$, S. Moghadam ${ }^{1}$, A. Arbab $^{1}$ and H. Vatankhah ${ }^{2, *}$ \\ ${ }^{1}$ Department of civil engineering, The Institute of Higher Education of Eqbal Lahoori, \\ Mashhad, Iran \\ ${ }^{2}$ University of Applied Science and Technology (UAST), Mohandesan Center, Iran
}

Published online: 15 May 2016

\begin{abstract}
Polymer concretes depending on the type of used polymer have good mechanical characteristics like high compressive strength and strain- stress proper behavior and increase lifetime and strength against concrete environmental factors. Therefore, they can be used for strengthening and retrofitting reinforced concrete structures.

This paper investigates the compressive strength of polymer concretes, strain-stress behavior, elasticity modulus and bond of polymer concrete to cement. Also is compared cubic and cylinder specimen of concrete cement and polymer with different percentages of polyester. Results showed that polymer concrete with $18 \%$ polyester has the highest compressive strength and the best strain- stress behavior and in terms of bond to concrete shows proper functioning.
\end{abstract}

Keywords: polyester; compressive strength; strain-stress behavior; bond.

Author Correspondence, e-mail: moghadam_soroush@yahoo.com

doi: http://dx.doi.org/10.4314/jfas.v8i3s.238 


\section{INTRODUCTION}

Concrete is also a cheapest and most widely used building materials that low price and proper compressive strength is main reason of general acceptance, But concrete have defects such as high density, low tensile strength, destruction due to freezing, destruction of surface layer, because of long-term atmospheric factors, no insulation against heat and low resistance against chemical material [1].

Polymer concrete is part of a group of concretes that use polymers to supplement or replace cement as a binder. Polymer concrete contains a polymer, mineral fillers, and pebbles. Most using polymers in polymer concretes generally are based on polyester, epoxy, vinyl ester, polyurethane, and monomeric methyl methacrylate. In addition, polymers of furan, furan epoxy, carbamide and calcium silicate also have a wide application [2]. Select polymer for concrete is depending on the performance required, strength, the bond of polymer to aggregate, waterproofing and resistance requirements against chemical attacks [3].

Valore and Naus [4] by using polyester resin, vinyl ester, and epoxy showed that compressive strength as a function of concrete density increased. Vipulanandan and Mebarika [5] showed that the concrete bending strength will be increasing by increasing polyester resin. Also said that add glass fiber to polymer concrete increases concrete endurance and strength. Maksimov et al [6] said that compressive strength of polymer concrete with polyester resin is in the range of 90-180 MPa. Orak [7] said that by using polyester resin, water distributor of polymer concrete is 4 to 7 times, more than cast iron. Rebeiz et al [8] showed that if in the polymer concrete with polyester resin, $15 \%$ of the sand replacing by fly ash, the amount of compressive strength increases up to $30 \%$.

In this study, concrete samples by using polyester resin are built and their characteristics are compared to normal concrete, the purpose is that to achieve the best percentage of polyester resin to get proper mechanical characteristics especially in concrete compressive strength.

\section{MATERIALS}

Polyester is the paste with high mechanical resistance, good bending to aggregate and proper strength to heat cycles and chemicals, but its consumption caused concrete shrinkage [9].The 
polymer used in this article is polyester with peroxide as hardener and Cobalt as an accelerator. The first step in making polymer concrete is a combination of monomer polyester with hardener for the formation of the polymer. The role of hardener is connectivity of monomer molecules and forming a high chain of the polymer. Since the polymerization may be time-consuming, cobalt is used to accelerate the process of forming a polymer. Figure 1 represents monomer polyester, hardener, and Cobalt accelerator.

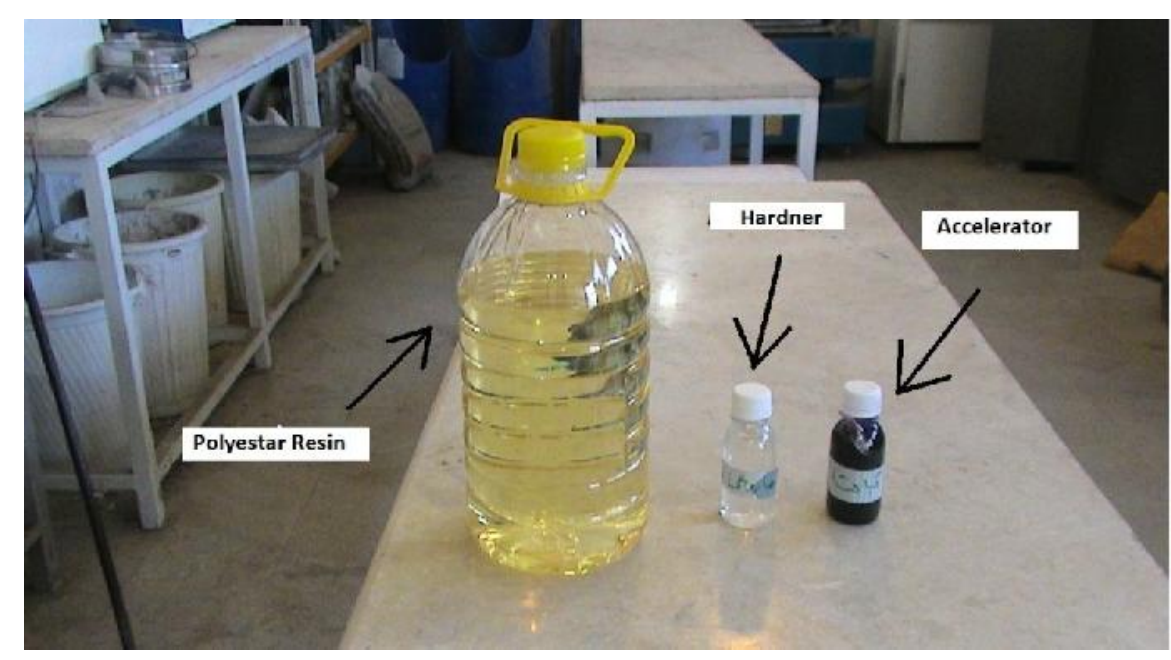

Fig.1. Monomer polyester with hardener and accelerator

In addition to making the polymer, cement is used as filler and aggregate in mix design of polymer concrete. For checking the amount of polymer (the percentage by weight of cement) acted to make 15 cubic specimens $150 \times 150 \times 150 \mathrm{~mm}$ and 12 cylinder specimens $150 \times 30 \mathrm{~mm}$ that all of the samples was tested at the age of 28 days. Table (1) shows the percent of the polymer used for the samples under test.

Table 1. Cubic and cylinder specimens

\section{Cylinder specimen (for bonding test)}

3 specimens of concrete cement-cement

3 specimens of concrete cement-polymer $18 \%$

\section{Cubic specimen}

3 specimens of control concrete (cement)

3 specimens of polymer concrete $16 \%$

3 specimens of polymer concrete $18 \%$

3 specimens of polymer concrete $20 \%$

3 specimens of polymer concrete $22 \%$ 
In figure 2 cubic specimens for checking compressive strength and cylinder specimen for checking bonding between polymer concrete and normal concrete are shown. Cylinder specimens are built in this form that first half volume of mold filled by concrete cement as the face on sample formed angle $30^{\circ}$ by the vertical line. After that concrete cement contains enough consolidation, another cylinder mold was filled with polymer concrete.
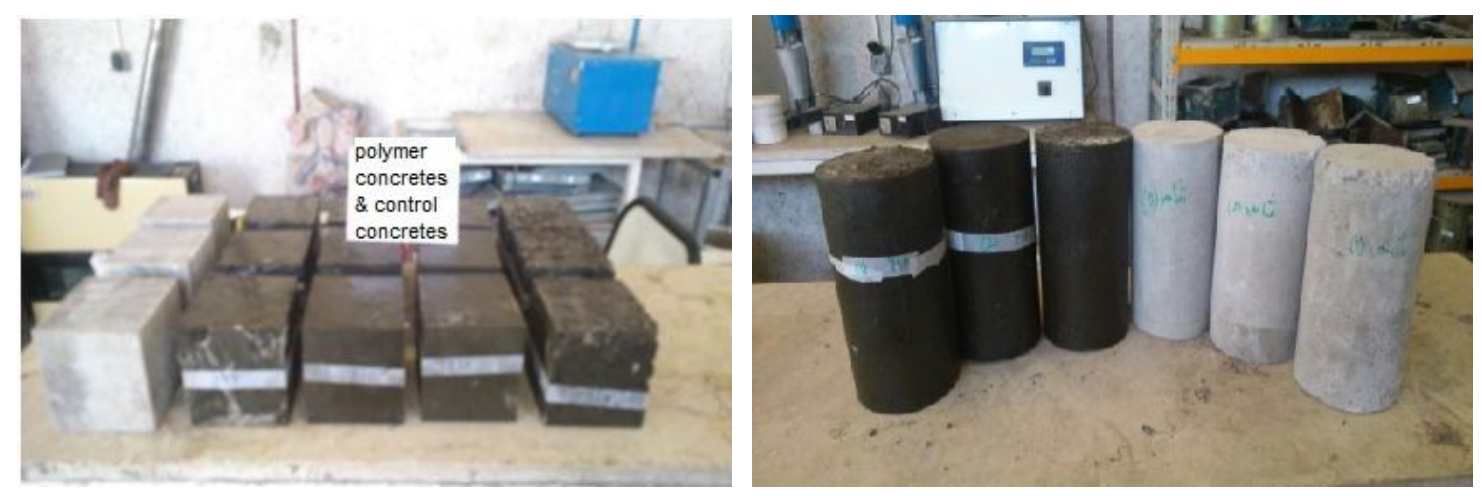

Fig.2. Built cubic and cylinder specimens

Mix design of polymer concrete depends on required concrete slump and resistance. Mix design that is used in polymer concrete and concrete cement is explained in table 2. For polymers, weight percentages in the range of 16 to 22 percent regard to cement are selected and for all of the specimens, cement is used as filler that it is $250 \mathrm{~kg} / \mathrm{m}^{3}$.

Table 2. MIX design of polymer concrete and control cement concrete

\begin{tabular}{|c|c|c|c|c|c|}
\hline $\begin{array}{l}\text { Material } \\
\text { concrete }\end{array}$ & $\begin{array}{l}\text { Gravel } \\
\text { kg/m }\end{array}$ & $\begin{array}{l}\text { Sand } \\
\mathrm{kg} / \mathrm{m}^{3}\end{array}$ & $\begin{array}{c}\text { Cement } \\
\mathrm{kg} / \mathrm{m}^{3}\end{array}$ & $\begin{array}{l}\text { Polyester } \\
\text { (to cement) }\end{array}$ & $\begin{array}{l}\text { Water } \\
\mathrm{kg} / \mathrm{m}^{3}\end{array}$ \\
\hline control & 884 & 356 & 250 & - & 125 \\
\hline Polymer $16 \%$ & 884 & 356 & 250 & $16 \%$ & - \\
\hline Polymer18\% & 884 & 356 & 250 & $18 \%$ & - \\
\hline Polymer $20 \%$ & 884 & 356 & 250 & $20 \%$ & - \\
\hline Polymer $22 \%$ & 884 & 356 & 250 & $22 \%$ & - \\
\hline
\end{tabular}




\section{RESULTS AND DISCUSSION}

Tests were conducted on samples contain compressive strength test and bond test of polymer concrete to cement [10](According to ASTM C882). Based on these two tests, the secondary results contain strain- stress curve, elasticity modulus and strength index were determined for samples. The elasticity modulus obtains from drawing a tangent to the area of the strainstress curve of each sample and calculating the slope of the tangent. Also, the strength index of each sample is equal to the area under its stress-strain curve.

All of the cubic specimens were placed in jack machine of crushing concrete and loading action were done on them, at 10 seconds intervals the amount of power were registered and this process repeated until the maximum power and fracture. As regards machine, loading velocity was selected on $2 \mathrm{~mm} / \mathrm{min}$ and strain rate per 10 seconds until the fracture is calculable. Therefore, the amount of strain and stress of each of the samples was calculated per10 seconds and each time has been averaged from three specimens for 1 percent special polymer. The resulting number as stress concrete was registered at that time, average strainstress curves of each of the percentage of the polymer have been plotted for comparison in figure 5. Figure 1 show that polymer concrete with $18 \%$ have the most pressure strength and is $74.1 \mathrm{MPa}$. This amount for normal concrete calculated according to mix design, it is 26.7 MPa. Polymer concrete strength ratio $18 \%$ respect to normal concrete is 2.775 .It showed that increasing of compressive strength is around $177.5 \%$. 


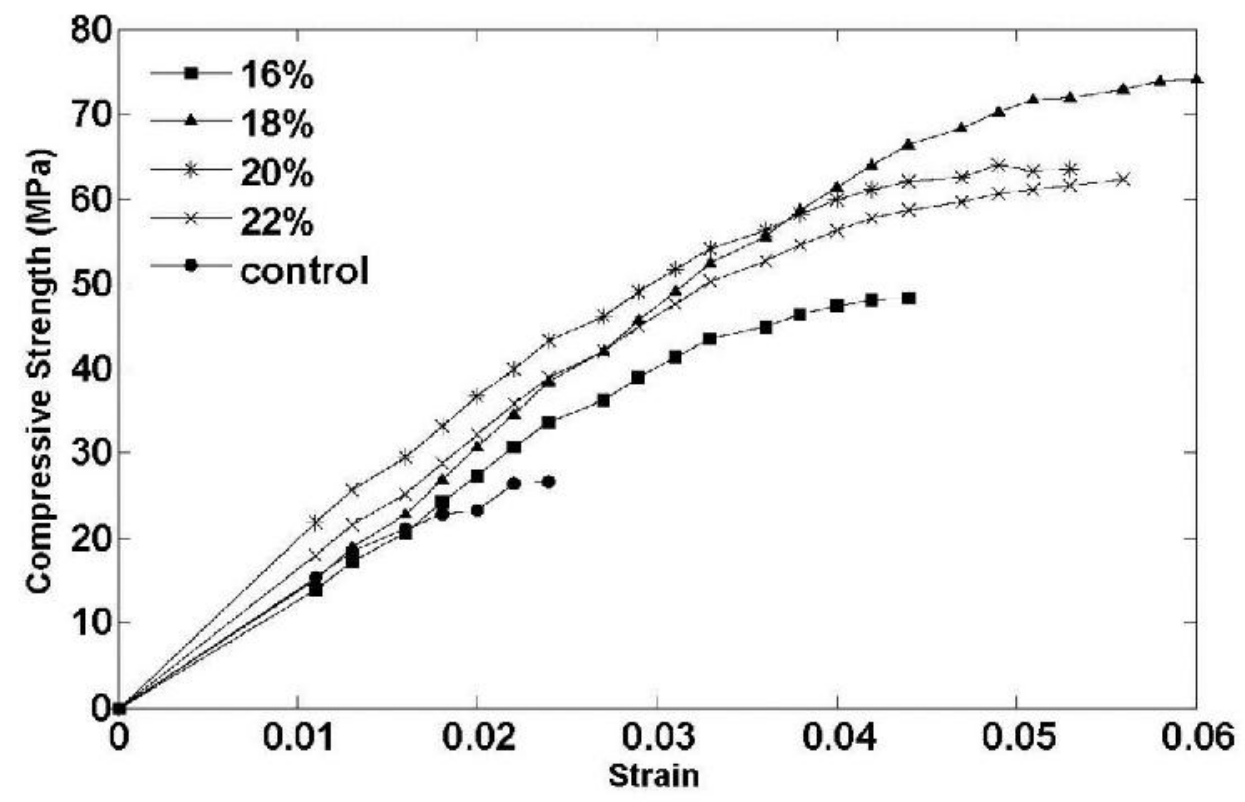

Fig.3. strain-stress diagram of average polymer cubic specimens (with different percent) and cement

Based on the figure 3 maximum tolerated stress by MegaPascal, modulus of elasticity and index of toughness for the average per concrete are obtained that are shown in table 3 , the amount of table represents the increase concrete toughness by using polymer.

Polymer concrete in addition to increasing the maximum compressive strength could withstand more stress in comparison to normal concrete. Meanwhile, concrete with polymer $22 \%$ has the fewest elasticity modulus than other polymer concrete but it shows more plasticity according to Figure 3.

Table 3. Stress, elasticity modulus, strength index of cubic specimens

\begin{tabular}{|c|c|c|c|c|c|}
\hline Concrete & Contro & Polymer16\% & Polymer18\% & Polymer20\% & Polymer22\% \\
\hline characteristic & 1 & & & & \\
\hline Stress(MPa) & 26.7 & 48.2 & 74.1 & 63.4 & 62.2 \\
\hline elasticity & 1156 & 1223 & 1424 & 1258 & 1140 \\
\hline \multicolumn{6}{|l|}{ module } \\
\hline strength index & 0.39 & 1.267 & 2.626 & 2.292 & 2.231 \\
\hline
\end{tabular}


The bond test of polymer concrete to cement, all cylinder specimens were placed into the jacking machine of concrete crushing and were loaded with maximum power and fracture. After averaging of the polymer specimens $18 \%$ determined that cement- polymer specimens are broken in the maximum load $8133 \mathrm{~kg}$ whereas cement-cement specimens are broken in $6109 \mathrm{~kg}$ load. This represents an increase of 33/13 percent bonding between the polymer and cement specimens that it indicates the power of their use for retrofitting works.

\section{CONCLUSION}

From the outcome of our investigation, it is possible to conclude that compressive strain, elasticity modulus, and strength index of polymer concretes are more than concrete cement. Also among polymer concretes and different percent of the polymer, polymer concrete with $18 \%$ higher polyester resin showed better results. Also, it can be seen that with the percentage of resin to $18 \%$, compressive stress, elasticity modulus, and strength index will increase, but after $18 \%$ began to fall out.

The resulting bonding between normal concrete and polymer concrete was found that polymer concrete bond to cement respect to concrete cement to cement is more. The results show that this concrete is a good option for retrofitting works.

\section{REFERENCES}

[1] Advanced concrete technology, Z. Li, John Wiley \& Sons. , 2011

[2] Ohama, h., "Recent progress in concrete -polymer composite", Advancement based materials, vol5, no.2, 1997.

[3] ACI Committee 548, 2009. ACI 548, IR-09 Guide for the use of polymers in concrete. [4]R. Valore and D. J. Naus, "Resin bound aggregate material systems in proceedings of the 1 st international congress on polymer concrete-polymer in concrete, pp.216-222, London, U.K, 1975.

[5] C. Vipulnandan and S. Mebarkia, “Aggregates, fibers and coupling agents in polymer concrete" in the proceeding of the 1st materials Engineering conference, pp. 785-794, Denver colorado, Agust 1990. 
[6] R. D. Maksimov, L. Jirgens, and E. Plume," mechanical properties of polyester polymer concrete", mechanics of composite materials, vol. 35, no .2 pp.99-110, 1999.

[7] S. Orak, "Investigation of vibration damping on polymer concrete with polyester resin" Cement and Concrete Research,vol.30,no.2,pp.171-174,2000

[8] K. S. Rebeiz, S. P. Serhal, and A. P. Croft "Properties of polymer concrete using fly ash" journal of materials in civil Engineering vol.16, no .1, pp.15-19, 2004.

[9] Polymer modified concrete: world experience and potential for Bangladesh, M.A.Islam, M. M. Rahman and M. Ahmed, January 2011, the Indian concrete journal.

[10] ASTM.C 882, 2008 "standard test method for the bond strength of epoxy resin systems used with concrete by slant with shear.

\section{How to cite this article:}

Ghiami Bajgirani A, Moghadam S, Arbab A and Vatankhah H. The mechanical characteristics of polymer concrete using polyester resin. J. Fundam. Appl. Sci., 2016, 8(3S), 571-578. 